\title{
Immunocompetent patient with Nocardia abscessus brain abscess: Case report and review of the literature
}

\author{
Sultan Alsalmi ${ }^{* 1,2}$, Abdulgadir Bugdadi ${ }^{3,4}$, Abdu Alkhayri ${ }^{5,6}$, Louis Chenin $^{1}$, Johann Peltier ${ }^{1}$ \\ ${ }^{1}$ Department of Neurosurgery, Amiens University Medical Center, Amiens, France \\ ${ }^{2}$ Department of Neurosurgery, Imam Abdulrahman Bin Faisal University, Dammam, Saudi Arabia \\ ${ }^{3}$ Department of Neurosurgery, Faculty of Medicine, Sorbonne University, Paris, France \\ ${ }^{4}$ Department of Surgery, Faculty of Medicine, Umm Al Qura University, Makkah Almukarramah, Saudi Arabia \\ ${ }^{5}$ Department of Neurosurgery, Faculty of Medicine, University Paris Descartes, Paris, France \\ ${ }^{6}$ Department of Neurosurgery, King Faisal Medical City, Abha, Saudi Arabia
}

Received: May 10, 2018

DOI: $10.5430 /$ css.v4n1p17
Accepted: May 17, 2018

Online Published: May 21, 2018

\begin{abstract}
Nocardia cerebral abscess is uncommon. It accounts for $1 \%-2 \%$ of all cerebral abscesses. It typically occurs in immunocompromised patients but cases in immunocompetent hosts been reported. Diagnosis of Nocardia brain abscess can be difficult and misleading. In this report we report a case of Nocardia abscessus brain abscess that was misdiagnosed initially as brain tumor. The patient has been successfully managed medically along with surgical evacuation twice.
\end{abstract}

Key Words: Nocardia, Nocardiosis, Nocardia abscessus, Brain abscess, Brain abscess in immunocompetent patient, Cerebral infection

\section{INTRODUCTION}

Nocardiosis is a localized or disseminated infection caused by the soil-borne aerobic actinomycete Nocardia. ${ }^{[1-5]}$ There are more than 50 species of Nocardia with around 33 species causing diseases in humans. ${ }^{[1,4,6]} N$. asteroides complex is considered the common source of nocardiosis. Nocardia asteroides complex includes: Nocardia asteroides, brasiliensis, otitidiscaviarum, transvalensis, farcinica and Nocardia nova ${ }^{[7]}$ Nocardiosis presents most commonly as pulmonary disease, as inhalation is the most common method of infection, which may be followed by dissemination to multiple sites by hematologic spread. ${ }^{[8]}$ Nocardia cerebral abscess accounts for only $1 \%-2 \%$ of all cerebral abscesses and is mostly via hematogenous spread, but cases of primary central nervous system infections have been reported. ${ }^{[9-11]}$ Nocardia brain abscess typically occurs in immunocompromised patients and less commonly in immunocompetent hosts. ${ }^{[12]}$

We describe a case of an immunocompetent 34-year-old male with a Nocardia abscessus brain abscess and review similar reported cases in the literature.

\section{Case presentation}

A 34-year-old Moroccan gentleman presented to a local hospital complaining of headache for one month. The headache was mainly located at the right temporal region, constant and progressive in severity. It was associated with asthenia and disorientation in space and time. The patient denied history of fever. He complains of intermittent hands and abdomen pruritus 3 weeks prior to presentation. No pul-

\footnotetext{
* Correspondence: Sultan Alsalmi, M.B.B.S.; Email: Sultan.Alsalmi@ hotmail.com; Address: Department of Neurosurgery, Amiens University Medical Center, Avenue René Laennec, Salouel, 80054, Amiens cedex 1, France.
} 
monary complaints and denied any neurological symptoms. Past medical/surgical history is significant for two surgical interventions of left foot, one for osteoma of the second toe and the other for hallux valgus with postoperative complication in the form of algoneurodystrophy. He traveled to Morocco twice two years prior to presentation. The patient is a sportive person who enjoys boxing, walking and hunting in the forests. There is a positive history of contact with stagnant water during a hunting trip in the forest.

The patient underwent CT scan and Magnetic Resonance Imaging (MRI), which showed right temporal mass surrounded by enormous cerebral edema associated with midline shift. A tumorous lesion was suspected and the patient started on Methylprednisolone $120 \mathrm{mg}$ once daily. He was then transferred to Amiens University Health Center (CHUAmiens).

On arrival to CHU-Amiens, the patient was vitally stable, afebrile, and alert but disoriented to time and place. He had a normal pulmonary and cardiac examination. The abdomen was soft with neither tenderness nor rigidity. There was no motor, sensory or cranial nerve deficits. Laboratory investigations revealed a C-reactive protein $12 \mathrm{mg} / \mathrm{dl}$, ESR of $10 \mathrm{~mm} / \mathrm{h}$, WBC count 15,200/microliter, HgB $14.4 \mathrm{~g} / \mathrm{dl}$, BUN $17 \mathrm{mg} / \mathrm{dl}$ and Creatinine $0.9 \mathrm{mg} / \mathrm{dl}$. Neutrophil function test, lymphocyte count, lymphocytes immunophenotyping, levels of immunoglobulin, C3 and C4 were normal. Human immunodeficiency, hepatitis $\mathrm{B}$ and hepatitis $\mathrm{C}$ viruses testing were negative. Formal ophthalmic examination revealed left homonymous hemianopsia. MRI done at the local hospital has been re-read by a neuroradiologist and revealed an intraaxial lesion in the right temporal lobe measuring $43 \mathrm{~mm} \times$ $40 \mathrm{~mm} \times 30 \mathrm{~mm}$ associated with significant mass effect on the right lateral ventricle and about $12 \mathrm{~mm}$ of midline shift. The lesion shows restricted diffusion. It has multiple microcystic appearance as evident on CT scan (see Figure 1) and T2-weighted MR imaging. It is surrounded by a peripheral hypointense rim on $\mathrm{T} 2$-weighted images with multi-loculated contrast enhancement (see Figure 2) which is suggestive of Nocardial brain abscess rather than a brain tumor. ${ }^{[13]}$ Based on these findings, Methylprednisolone was stopped immediately and the patient taken to the operating room urgently.

Initially the patient underwent abscess puncture and drainage under Neuronavigation guidance. Aspiration using a Sedan biopsy needle was unfortunately unsuccessful as the content was very viscous. Therefore, we were not able to evacuate the collection enough. We withdrew a scant amount of the abscess that enabled identification of the Nocardia by DNA sequencing method. It was susceptible to Imipenem/Cilastatin (Tienam), Amikacin and Trimethoprim/Sulfamethoxazole (Bactrim), Ceftriaxone and Minocycline.

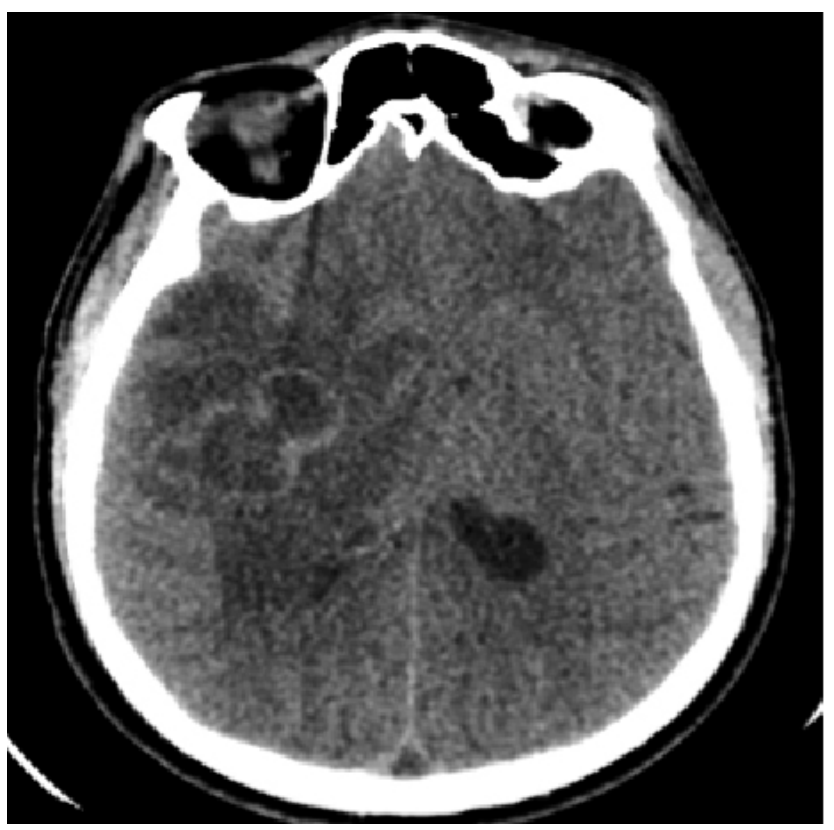

Figure 1. Non-injected axial CT scan showing the multicystic appearance

Postoperatively, the patient was started on intravenous Cefotaxime and Metronidazole empirically for three days until the culture and mass spectrophotometry showed $N$. abscessus. It was sensitive to all tested antibiotics except Erythromycin, Moxifloxacin, Levofloxacin, and Pristinamycine. The antibiotics then adjusted to intravenous Imipenem/Cilastatin (Tienam), Amikacin and Trimethoprim/Sulfamethoxazole (Bactrim). A week later, the patient was found very somnolent and confused. CT scan was done and showed lack of regression in the size of the abscess. Therefore, we decided to do good evacuation of the abscess through a small craniotomy. On day 10 of antibiotics initiation, Amikacin was changed to Minocycline and on Day 21, Bactrim had to be discontinued due to the development of neutropenia. Finally, after six weeks, Tienam was changed to Ceftriaxone. As part of the research for an etiology, Thoracoabdominopelvic CT scan was done that was negative except for an opacity and mediastinal adenopathy. Bronchial fibroscopy did not show anomalies and test of the bronchoalveolar lavage aspirate was totally negative including for Nocardia or evidence of alveolar proteinosis.

The patient had an uneventful hospital stay. The left homonymous hemianopsia improved. He was discharged after six weeks to continue on intravenous Ceftriaxone for an additional three months and oral Minocycline for at least one year. At one-year follow up, the patient was doing well, no recurrence manifested and cerebral MRI was negative apart from post-operative changes. 

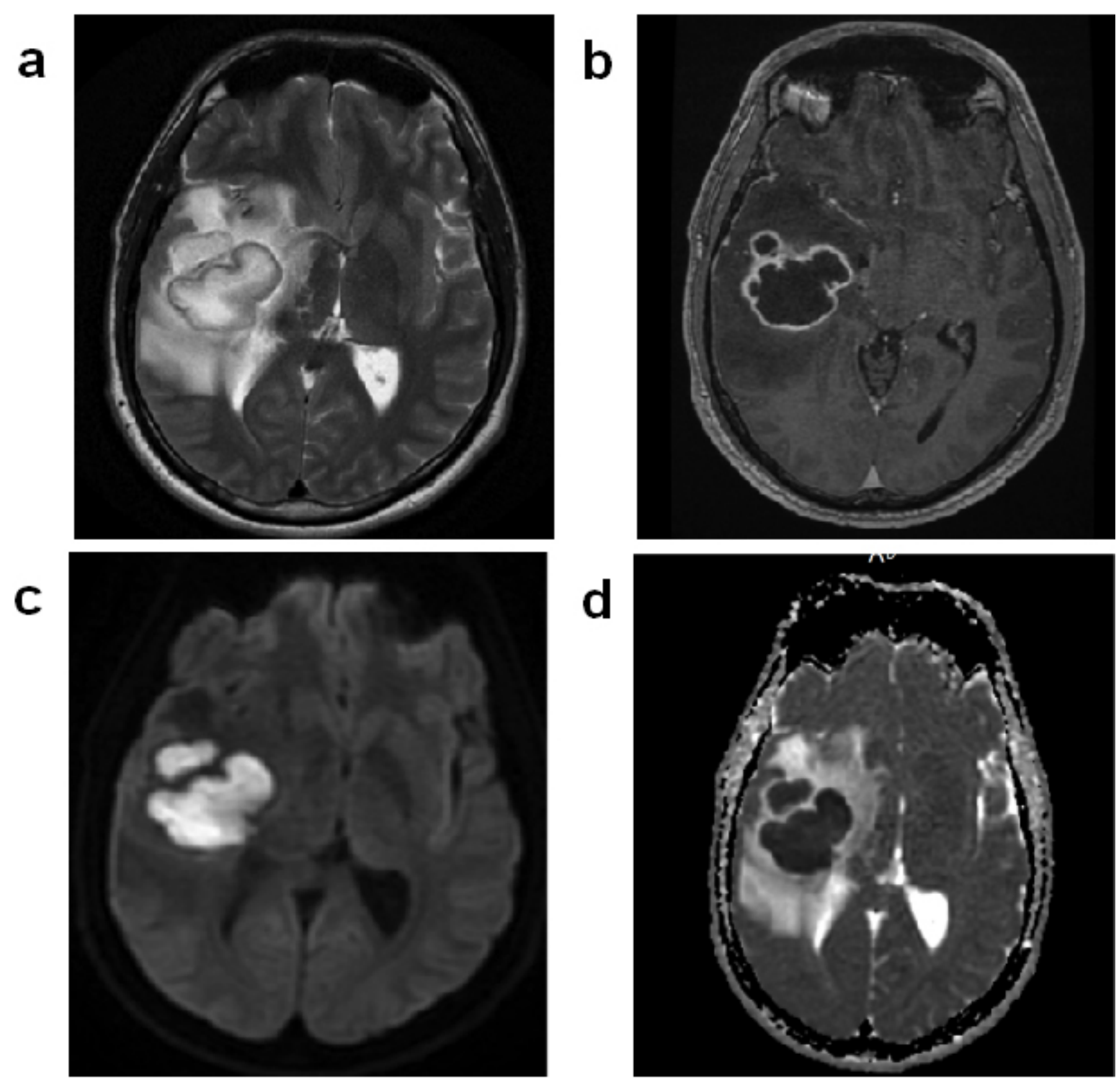

Figure 2. a. T2 MR sequence showing hyperintense mass with hypointense rim; $b$. T1 MRI with gadolinium showing rim enhancement; c. Diffusion MR sequence showing restricted diffusion; d. ADC map showing hypointensity confirming restricted diffusion

\section{Discussion}

Nocardia is an aerobic actinomycete gram-positive bacterium. It is typically an opportunistic organism that can cause local or systemic diseases in infected hosts. ${ }^{[3,5]}$ However, it can less commonly infect immunocompetent individuals. ${ }^{[1]}$ Nocardia include more than 80 species of which around 33 cause diseases in humans. ${ }^{[1,4,6]}$ It can be found in soil, decayed vegetable matters, dust particles, and aquatic environment. ${ }^{[14]}$ Variable mode of entries were reported including; ingestion of contaminated food material, cutaneous inoculation and inhalation. ${ }^{[3,5]}$ The exact incidence of nocardiosis Published by Sciedu Press

年 is not well established, as it is not a reportable organism and difficulty in diagnosis. ${ }^{[15]}$ The risk factors for the majority of nocardiosis cases are the causes of immunocomprised state including; glucocorticoid use, malignancy, HIV infection and organ and hematopoietic stem cell transplantation. ${ }^{[1,3,16]}$ Other conditions reported to be associated with nocardiosis are alveolar proteinosis, diabetes mellitus, alcoholism, inflammatory bowel disease and tuberculosis. ${ }^{[1,3,5,16-18]}$

Cerebral abscess is a focal inflammation and collection of infected materials within the brain parenchyma. Pathogen invasion can occur either by direct spread or hematogenous 
seeding. ${ }^{[19]}$ Direct spread such as from infected paranasal sinuses or otitis media. ${ }^{[20-24]}$ Hematogenous seeding can occur following bacteremia originating from different sources, for example, chronic pulmonary infection, skin infection or endocarditis. ${ }^{[25-27]}$ Nevertheless, in 20\%-40\% of cases no primary source can be found. ${ }^{[28,29]}$ Microbiologically, brain abscess can be caused by various pathogens depending mostly upon the source of the primary infection, age of the patient and his/her immunological status. ${ }^{[30,31]}$ By far, the most common pathogens causing cerebral abscess are Staphylococcus and Streptococcus species. ${ }^{[32]}$ However, various organisms can cause brain abscess. ${ }^{[32]}$ In one systemic review of 123 studies including 9,699 cases of brain abscess, only about $0.6 \%$ of abscesses were caused by Nocardia. ${ }^{[32]}$ However, the incidence of Nocardia brain abscess varies in the literature that mostly lies between $1 \%-2 \%$ of cases and it is predominantly seen in immunocomprised patients. ${ }^{[9-11]}$ Nevertheless, up to one third of nocardiosis cases can be seen in immunocompetent individuals. ${ }^{[1,3,11,16]}$ Based on animal studies, there are arguments that immunocompetent patients with Nocardia brain abscess might have inherent immune defect particularly of cell-mediated immunity. ${ }^{[2,11]}$ This theory needs to be formally investigated in human subjects. Different species of Nocardia can infect the central nervous system. ${ }^{[11]}$ The majority of the infecting species are $N$. asteroids, $N$. farcinica, $N$. cyriacigeorgica ${ }^{[11]}$ Less common species include $N$. transvalensis, $N$. brasilensis and $N$. otitidiscaviarum. ${ }^{[1]}$ There are case reports of infections by $N$. carnea, $N$. exalbida, N. nova, N. asiatica.$^{[11]}$ Mortality rate from Nocardia brain abscess depends upon the therapeutic modality: $7 \%$ with combined targeted antimicrobial therapy and neurosurgery; $22 \%$ with targeted antimicrobial therapy alone and $36 \%$ for patients treated with neurosurgery alone. ${ }^{[11]}$

N. abscessus has been defined in the year 2000 after redefinition of the Nocardia taxonomy based upon molecular speciation rather than biochemical speciation. ${ }^{[33-35]}$ Nocardiosis caused by $N$. abscessus is uncommon in comparison to that caused by other Nocardia species. It is reported to cause $15 \%-18 \%$ of nocardiosis cases. ${ }^{[36-38]}$ Few cases have been documented in humans including pericarditis, pulmonary infection, cutaneous and soft tissue lesions and brain abscess in immunocomprised patients. ${ }^{[39-44]}$ To our knowledge, $N$. $a b$ scessus brain abscess in an immunocompetent host has been reported five times in the literature. ${ }^{[10,13,45-47]}$ In this report we present a sixth case of cerebral abscess by $N$. abscessus in an immunocompetent patient.

Mortality from $N$. abscessus is reported to be as high as $31 \%-34.6 \%$ but this reported mortality was in infected immunocompromised patients. ${ }^{[46,48]}$ There is no reported mor- tality in the five reported cases of brain abscess caused by $N$. abscessus pathogen in the immunocompetent patients. ${ }^{[10,13,45-47]}$ Two of the cases were treated solely by antibiotic. ${ }^{[13,45]}$ The other three cases were treated by combinations of antibiotics and surgical evacuation. ${ }^{[10,46,47]}$ As all Nocardia species, laboratory identification might be challenging using routine culture methods. ${ }^{[1,2,4,15,34,48]}$ Four out of the five reported cases detailed the methods of microbiological detection of the organism and treatment specifications. ${ }^{[45-47]}$ All were partially acid-fast positive. Routine cultures were negative and the diagnosis of the $N$. abscessus was done by molecular methods except in one case where the culture yielded Nocardia. ${ }^{[10,45-47]}$ Duration of antibiotics treatment was variable ranging from 6 weeks to one year.

In our case, the diagnosis was made using DNA sequencing followed by culture and spectrophotometry. The patient was treated by neurosurgical intervention along with targeted antibiotic therapy for one year. The source of the infection was not evident indicating a possible primary infection. ${ }^{[9-11]}$ The history of contact with stagnant water and soil triggers possible dermatologic inoculation of the organism, nevertheless, no skin manifestations of nocardiosis found on history or clinical examination. It is noteworthy that the abscess capsule was very hard to pierce, a finding that was also noted in another reported case of $N$. abscessus brain abscess. ${ }^{[47]}$ As the abscess content was very viscous, a sufficient evacuation was not possible necessitating open surgical evacuation. Therefore, we recommend an open neurosurgical evacuation in cases of suspected N. abscessus or failure to sufficiently aspirate the content material due to viscosity.

\section{Conclusions}

This is the sixth reported case of cerebral abscess in an immunocompetent patient caused by $N$. abscessus. Due to rarity of the condition, no specific guidelines are available in the literature. Therefore, delay in diagnosis can occur unless a high index of suspicion is maintained. Prompt diagnosis is important, as the outcome seems better with prompt surgical evacuation and targeted antibiotic therapy. On the basis of increased incidence and reports of Nocardia brain abscess in both immunocompromised and immunocompetent patients, we recommend searching actively for Nocardia in brain abscess cases specially in situations - although not specific of multiloculated abscess on imaging, hard abscess capsule, negative routine cultures or viscous abscess content.

\section{AUTHORS' CONTRIBUTION}

The first two authors contributed equally to the paper.

\section{CONFLICTS OF INTEREST DISCLOSURE}

The authors declare they have no conflicts of interest. 


\section{REFERENCES}

[1] Mandell GL, Bennett JE, Dolin R, et al. Nocardia Species, in Mandell, Douglas, and Bennett's Principles and Practice of Infectious Diseases. Churchill Livingstone Elsevier; 2010. 3199 p. Available from: https://books.google.fr/books?id=SvRLA QAAIAAJ\&q=Bennett $\backslash \mathrm{T} 1 \backslash$ textquoterights+Principles+a nd+Practice+of+Infectious+Diseases\&dq=Bennett $\backslash \mathrm{T} 1 \backslash t$ extquoterights+Principles+and+Practice+of+Infectio us+Diseases\&hl=fr\&sa=X\&ved=0ahUKEwjKzcnD0o_bAhUO6a QKHdEzCYUQ6AEIMDAB

[2] Lerner PI. Nocardiosis. Clin Infect Dis. 1996; 22(6): 891-903; quiz 904-5. PMid: 8783685. https://doi.org/10.1093/clinids/ 22.6 .891

[3] Lederman ER, Crum NF. A case series and focused review of nocardiosis: clinical and microbiologic aspects. Medicine (Baltimore). 2004; 83(5): 300-13. https://doi.org/10.1097/01.md.0000 141100.30871 .39

[4] Brownelliott BA, Brown JM, Conville PS, et al. Clinical and Laboratory Features of the Nocardia spp. Based on Current Molecular Taxonomy. Clinical Microbiology Reviews. 2006; 19(2): 25982. PMid: 16614249. https://doi.org/10.1128/CMR.19.2.2 59-282. 2006

[5] Beaman BL, Beaman L. Nocardia species: host-parasite relationships. Clin Microbiol Rev. 1994; 7(2): 213-64. https ://doi .org/10.1 128/CMR. 7.2.213

[6] Roth A, Andrees S, Kroppenstedt RM, et al. Phylogeny of the Genus Nocardia Based on Reassessed 16S rRNA Gene Sequences Reveals Underspeciation and Division of Strains Classified as Nocardia asteroides into Three Established Species and Two Unnamed Taxons. Journal of Clinical Microbiology. 2003; 41(2): 851-6. PMid: 12574299. https://doi.org/10.1128/JCM.41.2.851-856.2003

[7] Kumar VA, Augustine D, Panikar D, et al. Nocardia farcinica brain abscess: epidemiology, pathophysiology, and literature review. Surgical Infections. 2014; 15(5): 640-6. PMid: 25126828. https ://doi.org/10.1089/sur.2012.205

[8] Kilincer C, Hamamcioglu MK, Simsek O, et al. Nocardial brain abscess: Review of Clinical Management. Journal of Clinical Neuroscience. 2006; 13(4): 481-485. PMid: 16678731. https://doi .or $\mathrm{g} / 10.1016 / \mathrm{j} \cdot \mathrm{jocn} \cdot 2005.04 .031$

[9] Lin YJ, Yang KY, Ho JT, et al. Nocardial brain abscess. Journal of Clinical Neuroscience. 2010; 17(2): 250-253. PMid: 20005722. https://doi.org/10.1016/j.jocn.2009.01.032

[10] Alijani N, Mahmoudzadeh S, Hedayat YM, et al. Multiple brain abscesses due to nocardia in an immunocompetent patient. Archives of Iranian Medicine. 2013; 16(3): 192. PMid: 23432175.

[11] Anagnostou T, Arvanitis M, Kourkoumpetis TK, et al. Nocardiosis of the central nervous system: experience from a general hospital and review of 84 cases from the literature. Medicine. 2014; 93(1): 19-32. PMid: 24378740. https://doi.org/10.1097/MD. 00000 00000000012

[12] Fellows G, Kalsi P, Martin A. Nocardia farcinica brain abscess in a patient without immunocompromise. British Journal of Neurosurgery. 2007; 21(3): 301-303. PMid: 17612924. https ://doi.org/10.1 $080 / 02688690701365770$

[13] Pyatigorskaya N, Brugieres P, Hodel J, et al. What is your diagnosis? Journal of Neuroradiology. 2010; 37(3): 192-195. PMid: 19783307. https://doi.org/10.1016/j.neurad.2009.07.007

[14] Goodfellow M, Williams S. Ecology of actinomycetes. Annual Reviews in Microbiology. 1983; 37(1): 189-216. PMid: 6357051. http s://doi.org/10.1146/annurev.mi.37.100183.001201

[15] Ambrosioni J, Lew D, Garbino J. Nocardiosis: updated clinical review and experience at a tertiary center. Infection. 2010; 38(2):
89-97. PMid: 20306281. https://doi.org/10.1007/s15010-0 09-9193-9

[16] Palmer DL, Harvey RL, Wheeler JK. Diagnostic and therapeutic considerations in Nocardia asteroides infection. Medicine (Baltimore) 1974; 53(5): 391-401. https ://doi.org/10.1097/00005792-1 97409000-00005

[17] Wallis RS, Broder MS, Wong JY, et al. Granulomatous infectious diseases associated with tumor necrosis factor antagonists. Clinical Infectious Diseases. 2004; 38(9): 1261. PMid: 15127338. https ://doi.org/10.1086/383317

[18] Abreu C, Rochapereira N, Sarmento A, et al. Nocardia infections among immunomodulated inflammatory bowel disease patients: A review. World Journal of Gastroenterology. 2015; 21(21): 64916498. PMid: 26074688. https://doi.org/10.3748/wjg.v21. i21. 6491

[19] Brouwer MC, Tunkel AR, Mckhann GM, et al. Brain abscess New England Journal of Medicine. 2014; 371(5): 447-456. PMid: 25075836. https ://doi.org/10.1056/NEJMra1301635

[20] Yen PT, Chan ST, Huang TS. Brain abscess: with special reference to otolaryngologic sources of infection. Otolaryngol Head Neck Surg 1995; 113(1): 15-22. https://doi.org/10.1016/S0194-599 8 (95) 70139-7

[21] Kangsanarak J, Fooanant S, Ruckphaopunt K, et al. Extracranial and intracranial complications of suppurative otitis media. Report of 102 cases. Journal of Laryngology \& Otology. 1993; 107(11): 999-1004. PMid: 8288994. https://doi.org/10.1017/S0022215100125 095

[22] Giannoni CM, Stewart MG, Alford EL. Intracranial complications of sinusitis. Laryngoscope. 1997; 107(7): 863-7. PMid: 9217120 https ://doi.org/10.1097/00005537-199707000-00005

[23] Giannoni C, Sulek M, Friedman EM. Intracranial complications of sinusitis: a pediatric series. Am J Rhinol. 1998; 12(3): 173-8. PMid: 9653474. https://doi.org/10.2500/105065898781390127

[24] Gallagher RM, Gross CW, Phillips CD. Suppurative intracranial complications of sinusitis. Laryngoscope. 1998; 108(11 Pt 1): 1635-42. PMid: 9818818. https ://doi .org/10.1097/00005537-19981 1000-00009

[25] Bakshi R, Wright PD, Kinkel PR, et al. Cranial Magnetic Resonance Imaging Findings in Bacterial Endocarditis: The Neuroimaging Spectrum of Septic Brain Embolization Demonstrated in Twelve Patients. Journal of Neuroimaging. 1999; 9(2): 78-84. PMid: 10208104. https ://doi.org/10.1111/jon19999278

[26] Patel KS, Marks PV. Multiple brain abscesses secondary to bronchiectasis. A case of 34 discrete abscesses in one brain. Clin Neurol Neurosurg. 1989; 91(3): 265-7. https ://doi.org/10.1016/0303-8 467 (89) 90123-6

[27] Fischer EG, Shwachman H, Wepsic JG. Brain abscess and cystic fibrosis. J Pediatr. 1979; 95(3): 385-8. https ://doi .org/10.101 6/S0022-3476(79) 80511-9

[28] Yang SY, Zhao CS. Review of 140 patients with brain abscess. Surg Neurol. 1993; 39(4): 290-6. https ://doi.org/10.1016/0090-3 019 (93) 90008-0

[29] Schliamser SE, Backman K, Norrby SR. Intracranial abscesses in adults: an analysis of 54 consecutive cases. Scand J Infect Dis. 1988; 20(1): 1-9. PMid: 3363298. https ://doi .org/10.3109/003655 48809117210

[30] Lakshmi V, Rao R, Dinakar I. Bacteriology of brain abscess-observations on 50 cases. Journal of Medical Microbiology. 1993; 38(3): 187-190. PMid: 7681113. https://doi.org/10.1 099/00222615-38-3-187

Published by Sciedu Press 
[31] Brook I. Aerobic and anaerobic bacteriology of intracranial abscesses. Pediatr Neurol. 1992; 8(3): 210-4. https ://doi.org/10.1016/ 0887-8994 (92) 90070-F

[32] Brouwer MC, Coutinho JM, van de Beek D. Clinical characteristics and outcome of brain abscess: systematic review and metaanalysis. Neurology. 2014; 82(9): 806-13. PMid: 24477107. https : //doi.org/10.1212/WNL.0000000000000172

[33] Valdezate S, Garrido N, Carrasco G, et al. Epidemiology and susceptibility to antimicrobial agents of the main Nocardia species in Spain. Journal of Antimicrobial Chemotherapy. 2016; 72(3).

[34] Yassin AF, Rainey FA, Mendrock U, et al. Nocardia abscessus sp. nov. Int J Syst Evol Microbiol. 2000; 50(4): 1487-1493. PMid: 10939654. https://doi.org/10.1099/00207713-50-4-1487

[35] Brown-Elliott BA, Conville P, Wallace RJ. Current status of Nocardia taxonomy and recommended identification methods. Clinical Microbiology Newsletter. 2015; 37(4): 25-32. https ://doi .org/10.1 016/j.clinmicnews. 2015.01.007

[36] Portolá O, Guitart R, Gómez F, et al. Epidemiology and clinical manifestations of infection due to Nocardia species in Tarragona, 1997-2008: Nocardia cyriacigeorgica is an emerging pathogen. Enfermedades Infecciosas Y Microbiología Clínica. 2009; 27(10): 585588. PMid: 19477044.https ://doi.org/10.1016/j .eimc. 200 9.02 .008

[37] Maraki S, Scoulica E, Nioti E, et al. Nocardial infection in Crete, Greece: review of fifteen cases from 2003 to 2007. Scandinavian Journal of Infectious Diseases. 2009; 41(2): 122-127. PMid: 19101858. https://doi.org/10.1080/00365540802651905

[38] Liu WL, Lai CC, Ko WC, et al. Clinical and microbiological characteristics of infections caused by various Nocardia species in Taiwan: a multicenter study from 1998 to 2010. European Journal of Clinical Microbiology \& Infectious Diseases. 2011; 30(11): 1341. PMid: 21461846. https://doi .org/10.1007/s10096-011-1227-9

[39] Wellinghausen N, Pietzcker T, Kern WV, et al. Expanded spectrum of Nocardia, species causing clinical nocardiosis detected by molecular methods. International Journal of Medical Microbiology. 2002; 292(3): 277-282. PMid: 12398218. https://doi.org/10.1078/ 1438-4221-00208
[40] Lai CC, Tsai HY, Ruan SY, et al. Fatal pneumonia and empyema thoracis caused by imipenem-resistant Nocardia abscessus, in a cancer patient. Journal of Microbiology Immunology \& Infection. 2015; 48(6): 706-708. PMid: 23523047. https://doi.org/10.1016/j jmii.2013.01.005

[41] Kageyama A, Yazawa K, Kudo T, et al. First isolates of Nocardia abscessus from humans and soil in Japan. Japanese Journal of Medical Mycology. 2004; 45(1): 17-21. PMid: 14765097. https : //doi.org/10.3314/jjmm.45.17

[42] Horré R, Schumacher G, Marklein G, et al. Mycetoma due to Pseudallescheria boydii and co-isolation of Nocardia abscessus in a patient injured in road accident. Medical Mycology. 2002; 40(5): 525527. PMid: 12462533. https://doi.org/10.1080/mmy .40.5.5 25.527

[43] Diego C, Ambrosioni JC, Abel G, et al. Disseminated nocardiosis caused by Nocardia abscessus in an HIV-infected patient: first reported case. Aids. 2005; 19(12): 1330-1. PMid: 16052092. https : //doi.org/10.1097/01.aids.0000180108.96135.25

[44] Atzori L, Pau M, Aste N. Multiple cutaneous abscesses revealing disseminated nocardiosis in a patient with chronic rheumatoid arthritis Cutis. 2014; 94(6): E25-8. PMid: 25566581.

[45] Marchandin H, Eden A, Jean-Pierre H, et al. Molecular diagnosis of culture-negative cerebral nocardiosis due to Nocardia abscessus Diagnostic Microbiology \& Infectious Disease. 2006; 55(3): $237-$ 240. PMid: 16626912. https://doi.org/10.1016/j.diagmicr obio. 2006.01 .023

[46] Farran Y, Antony S. Nocardia abscessus-related intracranial aneurysm of the internal carotid artery with associated brain abscess: A case report and review of the literature. J Infect Public Health 2016; 9(3): 358-61. PMid: 26724261. https ://doi.org/10.101 $6 / \mathrm{j} \cdot \mathrm{jiph} .2015 .11 .009$

[47] Al Tawfiq JA, Mayman T, Memish ZA. Nocardia abscessus brain abscess in an immunocompetent host. J Infect Public Health. 2013; 6(3): 158-61. PMid: 23668458. https://doi.org/10.1016/j . jiph.2012.11.012

[48] Munoz J, Mirelis B, Aragón L M, et al. Clinical and microbiological features of nocardiosis 1997-2003. Journal of Medical Microbiology. 2007; 56(Pt 4): 545. 